\title{
Dynamic Properties and Fatigue Life of Stone Mastic Asphalt Mixtures Reinforced with Waste Tyre Rubber
}

\author{
Nuha Salim Mashaan, Asim H. Ali, Suhana Koting, and Mohamed Rehan Karim \\ Center for Transportation Research, Faculty of Engineering, University of Malaya, 50603 Kuala Lumpur, Malaysia \\ Correspondence should be addressed to Nuha Salim Mashaan; nuhamashaan@siswa.um.edu.my
}

Received 26 May 2013; Accepted 8 September 2013

Academic Editor: Zhimin Liu

Copyright ( 2013 Nuha Salim Mashaan et al. This is an open access article distributed under the Creative Commons Attribution License, which permits unrestricted use, distribution, and reproduction in any medium, provided the original work is properly cited.

Today, virgin polymer modified asphalt mixes are comparatively more expensive for road pavement. One way to reduce the expense of such construction and to make it more convenient is the application of inexpensive polymer, such as waste polymer. The primary aim of this study was to investigate the effect of adding waste tyre rubber (crumb rubber modifier (CRM)) on the stiffness and fatigue properties of stone mastic asphalt (SMA) mixtures. Various percentages of waste CRM with size of $0.60 \mathrm{~mm}$ were added to SMA mixtures. Indirect tensile stiffness modulus test was conducted at temperatures of 5,25 , and $40^{\circ} \mathrm{C}$. Indirect tensile fatigue test was conducted at three different stress levels $(2000,2500$, and $3000 \mathrm{~N})$. The results show that the stiffness modulus of reinforced SMA samples containing various contents of CRM is significantly high in comparison with that of nonreinforced samples, and the stiffness modulus of reinforced samples is in fact less severely affected by the increased temperature compared to the nonreinforced samples. Further, the results show that CRM reinforced SMA mixtures exhibit significantly higher fatigue lives compared to the nonreinforced mixtures help in and promotion of sustainable technology by recycling of waste materials in much economical and environmental-friendly manner.

\section{Introduction}

1.1. Roadways Mix Design. Roadways are considered as one of the most important elements of infrastructure. They play an essential role in our daily lives for the present and in the future. Thus, highway construction engineers must consider the primary user's requirements of safety as well as the economy. To achieve this goal, highway construction designers should take into account three fundamental requirements which include environmental factors, traffic flow, and asphalt concrete mixtures materials.

In asphalt concrete (AC), bitumen as a binder serves two major functions in road pavement: first, to hold the aggregates firmly and, second, to act as a sealant against water. However, due to some distresses like fatigue failure, the performance and durability of bitumen are highly affected by changes with time in terms of its characteristics which can lead to the cracking of pavement [1].
The design of bituminous mixture involves the selection and proportioning of materials to obtain the desired properties in the finished product. Asphalt concrete (AC) is designed to resist rutting, fatigue, low temperatures, cracking and other distresses. The serious distresses associated with flexible pavements are cracking, which occurs at intermediate and low temperatures, and permanent deformation, which occurs at high temperatures. These distresses reduce the services of life of the pavement and elevate the maintenance costs [2].

The dynamic properties and durability of conventional asphalt, however, are deficient in resisting pavement distresses. Hence, the task of current asphalt researchers and engineers is to look for different kinds of polymer modified bitumen with rheological properties that would directly affect the asphalt pavement performance [3]. Due to an increase in service, traffic density, axle loading, and low maintenance services, road structures have deteriorated and are therefore subjected to failure more rapidly. To minimise 
the damage of pavement such as resistance to rutting and fatigue cracking, asphalt needs to be modified with selected polymer [3]. The use of virgin polymers such as styrenebutadiene-styrene (SBS) and styrene-butadiene rubber (SBR) in pavement construction will increase the construction cost as they are highly expensive materials. However, with the use of alternative waste materials such as crumb rubber modifier (CRM), it will definitely be environmentally beneficial, and not only can it improve the bitumen binder properties and durability, but it also has the potential to be cost effective [20, 23-26].

1.2. Novelty of Using Waste Polymer. Virgin polymer offers the possibility of producing mixtures that can resist both rutting and cracking; however, using virgin polymer is costly. Thus, using recycled polymer such as crumb rubber is a good alternative and is inexpensive. Also, it is considered as sustainable technology, that is, "greening asphalt" which would transform unwanted residue into a new bituminous mixture highly resistant to failure. Thus, utilising crumb rubber obtained from scrap automobile tyre is not only beneficial in terms of cost reduction but also has less ecological impact in keeping the environmental clean and to achieve better balance of natural resources.

Crumb rubber or waste tyre rubber is a blend of synthetic rubber, natural rubber, carbon black, antioxidants, fillers, and extender type of oils which are soluble in hot paving grade. Rubberised asphalt is obtained by the incorporation of crumb rubber from ground tyres in asphalt binder at certain conditions of time and temperature using either dry process (method that adds granulated or crumb rubber modifier (CRM) from scrap tires as a substitute for a percentage of the aggregate in the asphalt concrete mixture, not as part of the asphalt binder) or wet processes (method of modifying the asphalt binder with CRM from scrap tires before the binder is added to form the asphalt concrete mixture). There are two rather different methods in the use of tyre rubber in bitumen binders: first is by dissolving crumb rubber in the bitumen as binder modifier and second is by substituting a portion of fine aggregates with ground rubber that does not completely react with bitumen [4].

The main characteristic of rubber is its property of high elasticity which allows it to undergo large deformations from which almost complete, instantaneous recovery is achieved when the load is removed [5]. This property of high elasticity derives from the molecular structure of rubber. Rubber belongs to the class of materials known as polymers and is also referred to as an elastomer.

The properties of an elastomer rubber are as follows.

(i) The molecules are very long and are able to rotate freely about the bonds joining neighbouring molecular units.

(ii) The molecules are joined, either chemically or mechanically, at a number of sites to form a threedimensional network. These joints are termed crosslinked. (iii) Apart from being cross-linked, the molecules are able to move freely past one another; that is, the Van der Waal's forces are small.

Similar to bitumen, rubber is a thermoplastic, viscoelastic material, whose deformation response under load is related to both temperature and rate of strain. However, the deformation of rubber is relatively incentive to temperature change where at both low rates of strain and at temperature well above the ambient, the material remains elastic. The wider range of elastic behaviour of rubber compared to that of bitumen largely results from the cross-linking of the long rubber molecules. Rubber is also much more ductile than bitumen at low temperatures and high loading rates.

In 1950, the use of scrap tyre in asphalt pavement was reported [6]. In the early 1960, Charles Mc Donald working as Head Material Engineer for the city of Phoenix, Arizona, found that, after completing the mixing of crumb rubber with the conventional bitumen and allowing it to blend for mix duration of 45-60 minutes, there were new material properties produced. There was swelling in the size of the rubber particles at higher temperatures allowing for higher concentrations of liquid bitumen contents in pavement mixes [7]. Ever since then, the use of crumb rubber has gained interest in pavement modification as it is evident that crumb tyre rubber can improve the bitumen performance properties [8-11].

1.3. Stone Matrix Asphalt (SMA). Stone matrix asphalt (SMA) is a gap-graded hot mix that has gained popularity worldwide. SMA was first developed in Germany during the mid 1960s [12] to provide maximum resistance to rutting caused by the studded tyres on road. Earlier in the 1990s, SMA technology was widely used in the United State; however, most researchers' reports highlighted the mixtures, great possibility in rutting resistance but ignored any potential fatigue resistance of SMA [13]. In recognition of its excellent performance a national standard was set in Germany in 1984. Since then, SMA has spread throughout Europe, North America, and Asia Pacific. Several individual countries in Europe now have a national standard for stone mastic asphalt, and CEN, the European standards body, is in the process of developing a European product standard. Today, SMA is widely employed in many countries in the world as an overlay or surface course to resist induced load and its popularity is increasing amongst road authorities and the asphalt industry [14]. Due to the nature of SMA mixes (gap-graded) and the relatively large proportion of asphalt content, stabilisation is required to inhibit drain down of asphalt. These requirements can be achieved by adding fibre or polymer modifier, and since commercial polymer is not economical in terms of usage, therefore using recycled polymer such as CRM to the mixture has been found to be more economical and environmental friendly.

1.4. Asphalt and Stiffness. The dynamic stiffness or "resilient modulus" is a measure of the load-spreading ability of the bituminous layers; it controls the levels of the traffic-induced tensile strains at the underside of the lowest bituminous 
bound layer which are responsible for fatigue cracking, as well as the stresses and strains induced in the subgrade that can lead to plastic deformations [15].

Asphalt concrete (AC) should have high stiffness to be able to resist permanent deformation. On the other hand, the mixtures should have enough tensile stress at the bottom of the asphalt layer to resist fatigue cracking after many load applications. Figure 1 presents the orientation of principal stresses with respect to position of rolling wheel load.

Different testes and approaches have been used to evaluate asphalt concrete mixtures properties. Several material properties can be obtained from fundamental, mechanistic tests that can be used as input parameters for asphalt concrete performance models. Hadley et al. [17] evaluated the properties of asphalt concrete mixtures using the indirect tensile test. The main aspects, which can be characterised using indirect tensile test, are resilient elastic properties, fatigue cracking, and the properties related to permanent deformation. The elastic stiffness of the asphalt concrete mixtures can be measured using the indirect tensile test [2].

1.5. Fatigue Cracking of Asphalt. Fatigue is one of the most important distresses in asphalt pavement structure due to repeated load of heavy traffic services which occur at intermediate and low temperatures. There are different test methods used throughout the world to measure fatigue resistance for asphalt concrete mixtures.

A study by Aflaki and Memarzadeh [18] investigated the effects of rheological properties of crumb rubber on fatigue cracking at low and intermediate temperatures using different shear methods. The results showed that the high shear blending has more effect on improvement at low temperatures than the low shear blend.

Cracking is normally considered to be low temperature phenomena while permanent deformation is considered to be the predominant mode of failure at elevated temperatures. Cracking is mainly categorised into thermal cracking and load-associated fatigue cracking. Large temperature changes that occur in pavement usually result thermal cracking. This type of failure occurs when the thermally induced tensile stress, together with stresses caused by traffic, exceeds the tensile strength of the materials. It is often characterised by transverse cracking along the highway at certain intervals. Load-associated fatigue cracking is the phenomenon of fracture as a result of repeated or fluctuated stresses brought about by traffic loading. Traffic loads can cause a pavement structure to flex, and the maximum tensile strain will occur at the base of the bituminous layer. If this structure is inadequate for the imposed loading conditions, the tensile strength of the materials will be exceeded, and cracks are likely to initiate, which will be manifested as cracks on the surface of the pavement [14].

Raad and Saboundjian [19] investigated the fatigue life of asphalt concrete mixtures using the indirect tension fatigue test. During the indirect tension fatigue, the horizontal deformation was recorded as a function of load cycle. The test specimen was subjected to different levels of stress, in order, for a regression analysis on a range of values. This allowed the
TABLE 1: Properties of base binder grade 80/100 penetration.

\begin{tabular}{lc}
\hline Test properties & Test result \\
\hline Viscosity @ $135^{\circ} \mathrm{C}$ (pas) & 0.65 \\
$G^{*} / \sin \delta @ 64^{\circ} \mathrm{C}(\mathrm{kpa})$ & 1.35 \\
Ductility @ $25^{\circ} \mathrm{C}$ & 100 \\
Softening point @ $25^{\circ} \mathrm{C}$ & 47 \\
Penetration @ $25^{\circ} \mathrm{C}$ & 88 \\
\hline
\end{tabular}

development of the fatigue relationship between the number of cycles at failure $\left(N_{f}\right)$ and initial tensile strain $\left(\varepsilon_{t}\right)$ on a log$\log$ relationship. Fatigue life $\left(N_{f}\right)$ of a specimen is number of cycles to failure for asphalt concrete mixtures.

These models are created based on the relationship existing between stress, or strain, and fatigue life as are presented in the equations below:

$$
\begin{aligned}
& N_{f}=A\left(\frac{1}{\sigma}\right)^{n}, \\
& N_{f}=a\left(\frac{1}{\varepsilon}\right)^{b},
\end{aligned}
$$

where $N_{f}$ is the number of load cycles to failure, $r$ is the applied stress, $\varepsilon$ is the initial strain, and $A, n, a$, and $b$ are the regression coefficients (fatigue parameters) which are related to mixture properties.

\section{Materials and Methods}

2.1. Materials. For the purposes of this research investigations bituminous binder of $80 / 100$ penetration grade was used. Table 1 shows the characteristics of the bitumen used in this research. For the purpose of maintaining consistency of the CRM throughout the entire study, one batch of crumb rubber obtained from one source was solely used. In this study, in order to decrease segregation, fine crumb rubber $(0.6 \mathrm{~mm})$ was selected with specific gravity equivalent to 1.161 $[3,20]$. Crushed granite with SMA 20 aggregates was supplied from Kajang quarry (near Kuala Lumpur, capital of Malaysia) and was used throughout the study. The aggregate gradations and some physical properties of the adopted aggregate are illustrated in Tables 2 and 3, respectively.

2.2. Sample Fabrication. The specimens were prepared at optimum asphalt content (OAC) using Marshall method. Five various amounts of OACs have been obtained for five various CRM contents, $6.70 \%, 6.5 \%, 6.40 \%, 6.20 \%$, and $6.31 \%$ of OAC each for $0 \%, 6 \%, 12 \%, 16 \%$, and $20 \%$ (all by weight of aggregate particles) of CRM content, respectively.

To incorporate rubber in bituminous mix, a wet process was conducted. In the wet process, the rubberised bitumen samples were prepared by blending the CRM with bitumen of $80 / 100$ penetration grade (at the velocity speed of $200 \mathrm{rpm}$ at $180^{\circ} \mathrm{C}$ and 30 minutes) before mixing the resultant rubberised bitumen with aggregate [3].

Later, for preparing SMA mixtures, $1100 \mathrm{gm}$ of aggregate was placed in the oven and heated to $160^{\circ} \mathrm{C}$ for 2 hours. 


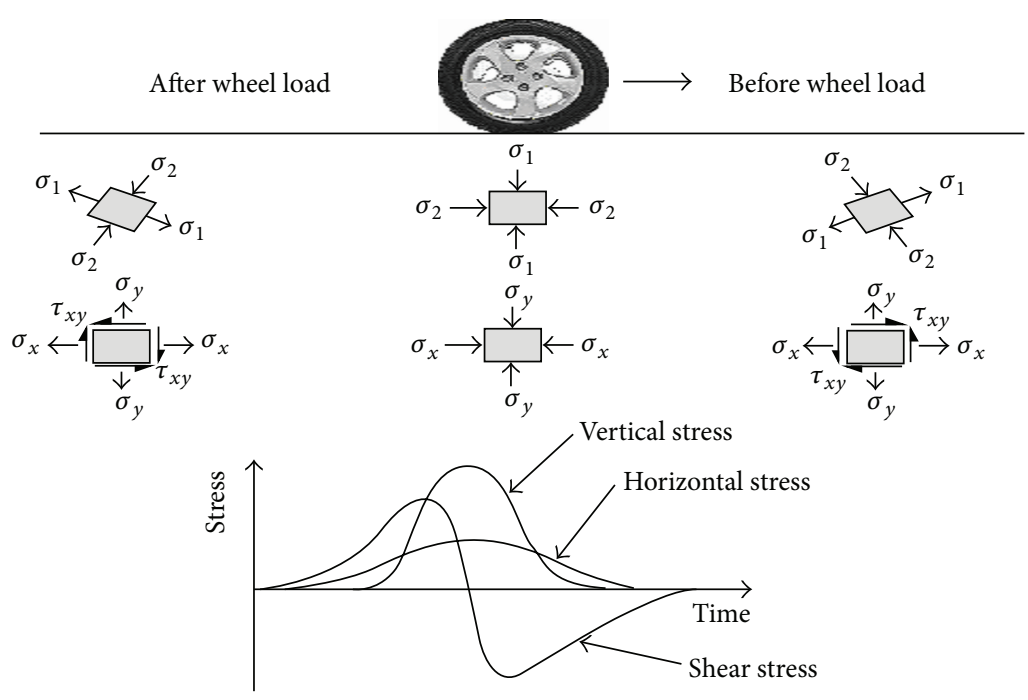

FIGURE 1: Stress beneath a rolling wheel load after [16].

TABLE 2: SMA 20 aggregate gradation.

\begin{tabular}{|c|c|c|c|c|c|}
\hline \multicolumn{6}{|c|}{ SMA 20} \\
\hline \multirow{2}{*}{ B.S Sieve } & \multicolumn{3}{|c|}{ \% Passing } & \multirow{2}{*}{$\%$ Retained } & \multirow{2}{*}{ Weight (G) } \\
\hline & Min. & Max. & Mid. & & \\
\hline 19 & 100 & 100 & 100 & 0 & 0 \\
\hline 12.5 & 85 & 95 & 90 & 10 & 110 \\
\hline 9.5 & 65 & 75 & 70 & 20 & 220 \\
\hline 4.75 & 20 & 28 & 24 & 46 & 506 \\
\hline 2.36 & 16 & 24 & 20 & 4 & 44 \\
\hline 0.6 & 12 & 16 & 14 & 6 & 66 \\
\hline 0.3 & 12 & 15 & 13.5 & 0.5 & 5.5 \\
\hline 0.075 & 8 & 10 & 9 & 4.5 & 49.5 \\
\hline \multirow[t]{2}{*}{ pan } & 0 & 0 & 0 & 9 & 99 \\
\hline & & & & 100 & 1100 \\
\hline
\end{tabular}

Rubberised bitumen required for the specimen was simultaneously heated up to temperature of $160^{\circ} \mathrm{C}$ for one hour. Once the aggregate and the bitumen reached the required temperature, the needed quantity of heated rubberised bitumen was added into the aggregates. Later, the crumb rubber modified bitumen binder and aggregates were mixed together (mixed by hands) at mixing temperature of $160^{\circ} \mathrm{C}$ until the aggregate was coated totally with bitumen. The mixture was transferred into a Marshall mould. The stainless steel thermometer was put in the centre of the mould, and the mixture was then ready for compaction at the temperature of $160 \pm 5^{\circ} \mathrm{C}$. All samples were subjected to 50 blows of compaction by Marshall hammer on each side of specimen. After finishing compaction, each sample was left to cool at room temperature before being extruded from the mould. Samples were removed from Marshall mould using hydraulic jack and stored at room temperature to be used later for further testing.

\subsection{Test Method}

2.3.1. Resilient Modulus Test. The dynamic stiffness or "resilient modulus" is a measure of the load-spreading ability of the bituminous layers; it controls the levels of the trafficinduced tensile strains at the underside of the lowest bituminous bound layer which are responsible for fatigue cracking, as well as the stresses and strains induced in the subgrade that can lead to plastic deformations [12]. The dynamic stiffness is computed by indirect tensile modulus test, which is a quick and nondestructive method.

This test covered the procedure for testing laboratory or filed recovered cores of bituminous mixtures to determine resilient modulus (MR) value using load indirect tensile test, under specified conditions of temperature, load, and load frequency. The test was conducted by applying compression loads with a prescribed sinusoidal waveform. The load was applied vertically in the vertical dimension plan of cylindrical specimen of bitumen sample. The resulting horizontal 
TABle 3: Physical properties of the crushed aggregate.

\begin{tabular}{lccr}
\hline Properties & Value & & Standard Test Method \\
\hline L.A. abrasion (\%) & $18.5 \%$ & $<30 \%$ & ASTM C-131 \\
Flakiness index (\%) & $5.0 \%$ & $<20 \%$ & BS 182: part 3 \\
Elongation index (\%) & $11.7 \%$ & $<20 \%$ & BS 182: part 3 \\
Soundness (\%) & $4.7 \%$ & $<12 \%$ & BS 12: part 3 \\
Impact value (\%) & $12.5 \%$ & $<15 \%$ & BS 12: part 3 \\
Polished stone value (\%) & $17.7 \%$ & $<30 \%$ & BS 12: part 3 \\
\hline
\end{tabular}

deformation of the specimen was measured with an assumed Poisson's ratio to calculate the resilient modulus values.

In the current study, the testing parameters were as follows:

(i) temperature $=5,25$, and $40^{\circ} \mathrm{C}$,

(ii) Poisson ratio $=0.34$,

(iii) force $=20 \times$ specimen depth,

(iv) rise time $=70 \mathrm{~ms}$,

(v) pulse period $=1 \mathrm{~s}$.

Horizontal tensile stress and stiffness modulus of AC mixtures can be obtained by the following:

$$
\begin{gathered}
\sigma_{\mathbf{x}}(\max )=\frac{(2 \times P)}{(\pi \times d x \times t)}, \\
S_{m}=\frac{(P \times(v+0.27))}{(H \times t)},
\end{gathered}
$$

where $\sigma_{\mathbf{x}}(\max )$ is the maximum horizontal tensile stress in the middle of specimen, $S_{m}$ is the stiffness modulus, $P$ is the applied vertical peak load, $H$ is the amplitude of horizontal deformation, $t$ is the average thickness of specimen, $d$ is the average diameter of specimen, and $m$ is Poisson's ratio. The indirect tensile test for resilient modulus of bituminous was carried out according to ASTM D1234 (1987), using the universal materials testing apparatus (UMATTA).

2.3.2. Indirect Tensile Fatigue Test. Fatigue test procedure is used to rank the bituminous mixture resistance to fatigue as well as being a guide to evaluate the relative performance of asphalt aggregate mixture and obtaining data and input for estimating the structural behaviour in the road.

During the fatigue test, modulus value decreased as indicated in Figure 2. Three phases were distinguished.

(i) Phase I: initially there is a rapid diminution of the modulus value.

(ii) Phase II: modulus variation is approximately linear.

(iii) Phase III: rapid decrease of the modulus value.

Damage is defined as any loss of strength that takes place in a specimen during a test.

The fatigue life is defined as the number of load cycling application (cycles) resulting in either disintegration or a permanent vertical deformation. A stiffness reduction of

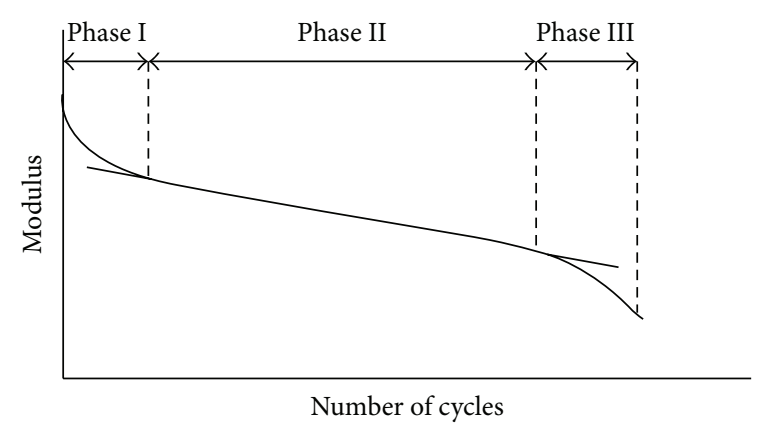

FIGURE 2: The three phases of fatigue test [21].

$50 \%$ was used to present the sample failure due to fatigue deformation.

Horizontal tensile strain also can be obtained as the function of stress and stiffnes of mixture by using (3):

$$
\varepsilon_{x}(\max )=\frac{\left(\sigma_{x} \max \right)(1+3 v)}{S_{m}} .
$$

$\boldsymbol{\varepsilon}_{x}(\max )$ is the maximum tensile strain at the center of specimen, $\sigma_{x}(\max )$ is the maximum tensile stress at the center of specimen, $S_{m}$ is the Stiffness modulus of specimen, and $v$ is Poisson's ratio.

Universal materials testing apparatus (UMATTA) was used to determine the repeated load indirect tensile test as a method of assessing the fatigue resistance of bituminous materials. In this research study, three cyclic loading forces were used $(2000,2500$, and $3000 \mathrm{~N})$, respectively. Loading cycle width was $100 \mathrm{~ms}$, load cycle repeated time was $500 \mathrm{~ms}$, and temperature was $25^{\circ} \mathrm{C}$ with axial displacement of about 5-6 mm.

\section{Results and Discussion}

3.1. Indirect Tensile Test Results (Stiffness Modulus). Resilient modulus is a primary variable in mechanistic design approaches for improved pavement structures, with regards to dynamic stresses and corresponding strains in pavement response [2].

Figure 3 illustrates the stiffness modulus variation plotted against temperature for reinforced SMA asphalt samples containing different percentages of crumb rubber and nonreinforced SMA samples. Each sample was prepared with optimum binder content. The results indicate that, when temperature is increased, the stiffness modulus of the asphalt 


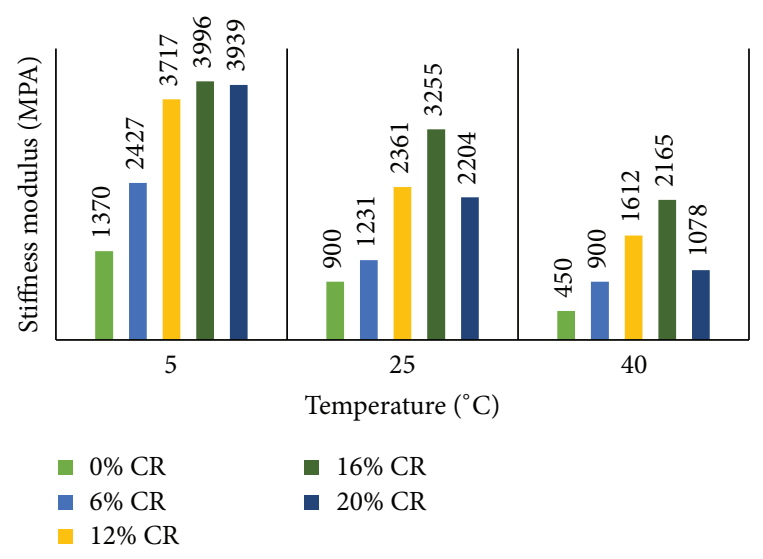

Figure 3: Stiffness modulus versus temperature.

samples is decreased. This occurs due to the change in the viscosity of bitumen as a result of the increased temperature which causes particle slippage in asphalt mixtures. This subsequently decreases the stiffness modulus of both the reinforced and nonreinforced samples. However, in comparison to the nonreinforced samples, the stiffness modulus of reinforced samples is found to be elevated as temperature increases with the presence of crumb rubber in the SMA asphalt samples, which can resist particle slippage. This, in turn, reduces the stiffness modulus rate of decrease. Hence, the rate of stiffness modulus is lower in reinforced samples. However, this positive effect is attenuated by an extreme increase in the CRM, and the gap generated between talus material grains causes the stiffness modulus to decrease [22].

IDT results (stiffness modulus) indicate that the increase in CRM content produces an improvement in the elastic properties of the studied mixtures. Modified bitumen improves the resilient modulus of asphalt mixtures compared to the control mixtures, due to higher viscosity and thick bitumen films leading to better resilience properties. Thus, modified bitumen produces asphalt concrete mixtures with improved stiffness and subsequently higher load bearing capacity. Furthermore, crumb rubber modified binders indicated lower temperature susceptibility. Mixes with modified binders indicated increased flexibility at decreased temperatures. This is due to the lower resilient modulus and higher stiffness as well as tensile strength at higher temperatures [2].

3.2. Indirect Tensile Fatigue Test (ITFT). The fatigue characteristics relating the accumulated strain with the number of cycles to failure for the SMA mixes with and without CRM reinforcement are illustrated in Table 4 and presented in Figures 3, 4, and 5 for various stress $(2000 \mathrm{~N}, 2500 \mathrm{~N}$, and 3000 N). Figures 4-6 display that the addition of CRM binder into SMA mixture improved the fatigue life and reduced the accumulated strain. SMA mixture reinforced with $12 \%$ CRM resulted in high fatigue life and hence lower strain value as shown in Table 4. Also, it appears that the higher the stress, the lower the fatigue life. At stress of 2000 and $2500 \mathrm{~N}$, the fatigue life increased by about $15 \%, 29 \%, 35 \%$, and $49 \%$ with the addition of $6-20 \%$ CRM, respectively,
TABLE 4: Fatigue test results.

\begin{tabular}{lccc}
\hline CRM & $\sigma(\mathrm{N})$ & $\mu \varepsilon$ & $N_{f}$ (Cycles) \\
\hline \multirow{3}{*}{$0 \%$} & 2000 & 1185 & 15,476 \\
& 2500 & 3354 & 3011 \\
& 3000 & 9893 & 345 \\
\hline \multirow{3}{*}{$6 \%$} & 2000 & 677 & 19,999 \\
& 2500 & 2735 & 2354 \\
& 3000 & 6656 & 490 \\
\hline \multirow{3}{*}{$12 \%$} & 2000 & 568 & 22566 \\
& 2500 & 2354 & 4657 \\
& 3000 & 4189 & 678 \\
\hline \multirow{3}{*}{$16 \%$} & 2000 & 889 & 18767 \\
& 2500 & 2890 & 2890 \\
& 3000 & 6788 & 543 \\
\hline \multirow{3}{*}{$20 \%$} & 2000 & 989 & 16566 \\
& 2500 & 3567 & 3567 \\
& 3000 & 7898 & 488 \\
\hline
\end{tabular}

whereas at stress of $3000 \mathrm{~N}$, the fatigue life increases by about $24 \%, 44 \%, 59 \%$, and $50 \%$. It seems that SMA mixtures tend to have lower fatigue lives at higher stress levels. This is probably due to chopped crumb rubber that are well distributed in bituminous matrix that highly resist the shear displacement and firmly prevent aggregate particles from any movement, thus increasing fatigue life by efficiently delaying crack propagation once the crack had been initiated $[1,2]$.

In order to obtain representation of the fatigue life, the regression equation for each mixture along with the regression parameters for various CRM and stress values are illustrated in Tables 5 and 6 . The basic fatigue life model confirms the aforementioned effects of crumb rubber content and stress levels on fatigue life. By having looked at fatigue model coefficients, some guidance may be provided. As strong evidence, the high $R^{2}$ values are reasonably indicative of good models accuracy. Meaning, the fatigue life is higher for the mixtures reinforced with crumb rubber as compared with original mixture (without crumb rubber). The relationship obtained is rational in that lower fatigue life as the stress levels are increased. Also, Table 4 indicates the variation of cyclic loading on the specimens containing varying percents of crumb rubber modifier. As the loading cycles are increased, the rate of tensile strain generation for both reinforced and nonreinforced specimens is found to be different. Crumb rubber modifier (CRM) leads to higher tensile strains in asphalt samples. The high elasticity and tensile strength of crumb rubber allow asphalt samples to deter creep-causedcracks as well as reducing the generation and propagation rate of microcracks. The high tensile strength evident in CRM can deter crack generation and the propagation of microcracks in asphalt samples [22]. However, the number of cycles to failure is different for asphalt samples which contain various percentages of crumb rubber. Reinforced samples tend to have longer fatigue life compared with nonreinforced samples. From Tables 5 and 6 , the behaviour model for asphalt samples containing various percentages of waste 
TABLE 5: Regression equations for fatigue life due to the variation of stress along with regression parameters.

\begin{tabular}{lccrr}
\hline Stress Values & Equation for & $K 1$ & $K 2$ & $R^{2}$ \\
\hline $2000 \mathrm{~N}$ & $N_{f}=2.276 \times 10^{5}(1 / \sigma)^{0.429}$ & $3.188 \times 10^{5}$ & 0.476 & 0.95 \\
$2500 \mathrm{~N}$ & $N_{f}=2.222 \times 10^{7}(1 / \varepsilon)^{1.112}$ & $2.624 \times 10^{7}$ & 1.090 & 0.92 \\
$3000 \mathrm{~N}$ & $N_{f}=1.344 \times 10^{5}(1 / \varepsilon)^{0.734}$ & $3.322 \times 10^{5}$ & 0.866 & 0.90 \\
\hline
\end{tabular}

TABLE 6: Regression equations for fatigue life due to the variation of CRM content at OBC along with regression parameters.

\begin{tabular}{|c|c|c|c|c|}
\hline CRM \% & Fatigue equations & $K 1$ & $K 2$ & $R^{2}$ \\
\hline 0 & $N_{f}=2.361 \times 10^{9}(1 / \varepsilon)^{1.725}$ & $2.261 \times 10^{9}$ & 1.345 & 0.96 \\
\hline 6 & $N_{f}=3.102 \times 10^{9}(1 / \varepsilon)^{1.631}$ & $3.002 \times 10^{9}$ & 1.898 & 0.92 \\
\hline 12 & $N_{f}=5.564 \times 10^{8}(1 / \varepsilon)^{1.613}$ & $4.664 \times 10^{8}$ & 1.212 & 0.90 \\
\hline 16 & $N_{f}=2.061 \times 10^{9}(1 / \varepsilon)^{1.616}$ & $2.161 \times 10^{9}$ & 1.676 & 0.92 \\
\hline 20 & $N_{f}=1.687 \times 10^{9}(1 / \varepsilon)^{1.699}$ & $1.487 \times 10^{9}$ & 1.888 & 0.94 \\
\hline
\end{tabular}

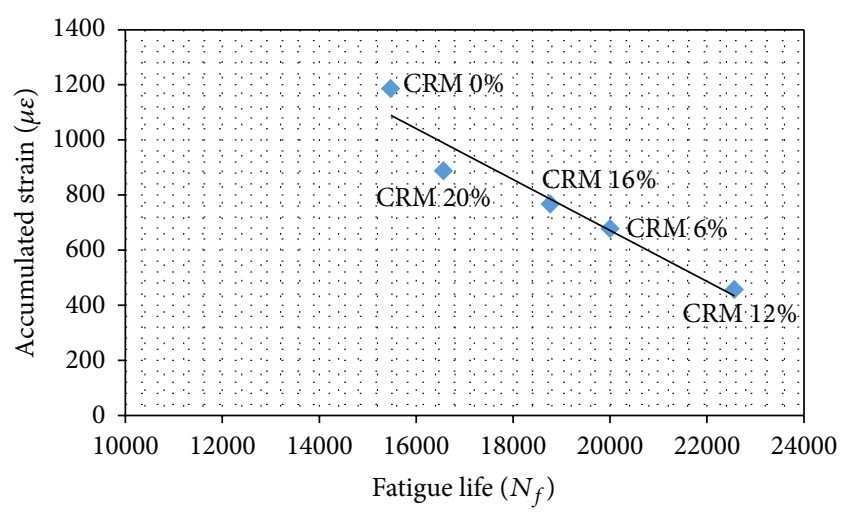

FIGURE 4: Fatigue life versus strain at $2000 \mathrm{~N}$ stress.

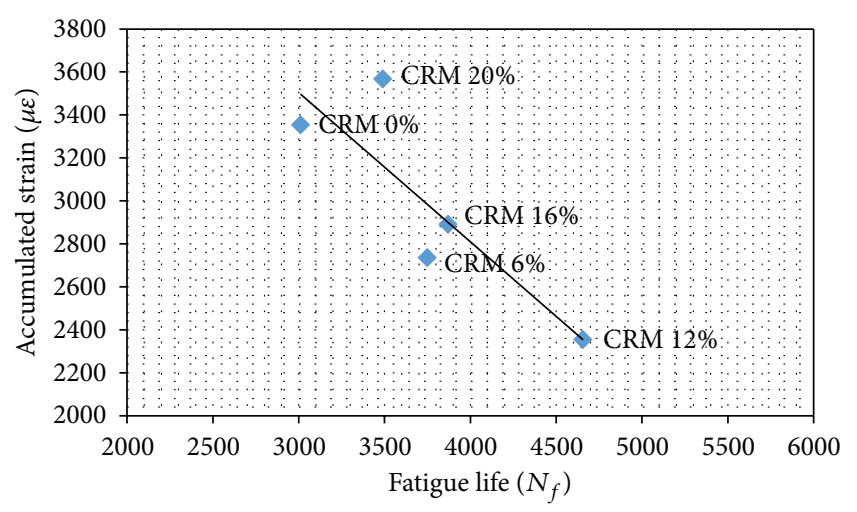

Figure 5: Fatigue life versus strain at $2500 \mathrm{~N}$ stress.

crumb rubber and the respective correlation coefficients are presented as well. It is observed that deviation from the optimum CRM content decreases the fatigue life of reinforced asphalt samples. The CRM asphalt deters tensile and vertical cracks from being effortlessly formed by horizontal tensile stresses and stops them from propagating [2-26].

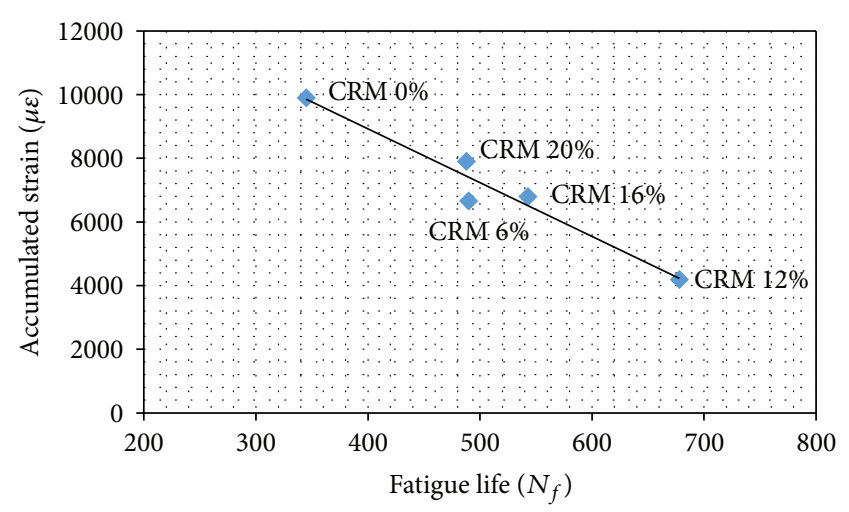

FIGURE 6: Fatigue life versus strain at $3000 \mathrm{~N}$ stress.

\section{Conclusion and Recommendations for Future Studies}

For a long time, the crack potential of pavements under various loading conditions and temperature variations has been an issue for the purposes of application of asphalt pavements. The maintenance and rehabilitation pricing is drastically increased when crack generation in asphalt pavement appears [14, 22]. Two primary solutions which have been put forth by researchers are, first, application of a thicker asphalt pavement and, second, producing an asphalt mixture with modified characteristics. To date a wide array of experiments has been conducted to investigate the effects of CRM reinforcement to resolve the issue of the cracking potential of asphalt pavement. For the purpose of this study, the use of crumb rubber modifier (CRM) in reinforcing asphalt pavement has been introduced and investigated thoroughly.

Based on the study conducted, the following conclusions can be derived.

(1) The stiffness modulus of reinforced SMA samples containing various contents of CRM is significantly high in comparison with that of nonreinforced samples. This increased stiffness modulus however is not 
related to increased brittleness of reinforced asphalt samples. The stiffness modulus of reinforced samples is in fact less severely affected by the increased temperature compared to the nonreinforced samples.

(2) With the presence of crumb rubber, the fatigue life of CRM reinforced samples is significantly improved. The resistance of waste tyre rubber to generated horizontal tensile stresses decreases the formation of vertical cracks and prevents these cracks from propagating along the diameters of asphalt samples. This in turn improves the fatigue life of reinforced samples.

(3) The relationships obtained are rational; the higher the stress level is, the lower the fatigue life is and the higher the accumulative strain is.

(4) Due to the addition of CRM, there has been a marked improvement in fatigue life thus being more considerable at higher stress level than at lower stress level. In particular, when heavy traffic load is applied, the enhancement of crumb rubber reinforced bituminous mix as a fatigue barrier is more remarkable.

(5) Regression models (fatigue equation) of fatigue life and accumulated strain due to different CRM content were developed for all samples. It was evident that high $R^{2}$ values are reasonably indicative of the model's accuracy.

(6) Apart from decreasing the pile up of waste materials, utilising these waste materials has improved the characteristics of engineering structure and materials in asphalt production and similar industries. Consequently, it has also reduced construction rehabilitation and maintenance costs.

(7) Since different conclusions have been drawn from this research project, a list of recommendations is summarised as follows for further investigations in the future:

(i) use of different type of aggregate, aggregate gradation, different mixing methods, and different compaction methods,

(ii) selection of different bitumen sources with various penetration grades and also the use of other kind of recycled polymer such as waste plastic bottle,

(iii) a comparative assessment of the cost incurred for pavement constructions utilising various modified asphalt with those constructed using conventional binder,

(iv) use scanning electron microscope images to evaluate binder-aggregate adhesion,

(v) conduct more studies for fatigue damage, including more mix variables and different rubber sizes to evaluate the effect of the particle size and texture of rubber.

\section{Conflict of Interest}

This paper has no conflict of interest.

\section{References}

[1] A. Mahrez, Properties of rubberised bitumen binder and its effect on the bituminous mix [M.S. dissertation], Faculty of Engineering, University of Malaya, Kuala Lumpur, Malaysia, 1999.

[2] F. K. M. Hamed, Evaluation of fatigue resistance for modified asphalt concrete mixture based on dissipate energy concept [Ph.D. thesis], Technische University, Darmstadt, Germany, 2010.

[3] N. S. Mashaan, The effect of crumb rubber modifier to the properties of and rheological behaviour of asphalt binder [M.S. dissertation], Faculty of Engineering, University of Malaya, Kuala Lumpur, Malaysia, 2012.

[4] Y. Huang, R. N. Bird, and O. Heidrich, "A review of the use of recycled solid waste materials in asphalt pavements," Resources, Conservation and Recycling, vol. 52, no. 1, pp. 58-73, 2007.

[5] A. N.S. Beaty, "Latex-modified bitumen for improved resistance to brittle fracture," Highways and Transportation, vol. 39, no. 9, pp. 32-41, 1992.

[6] D. I. Hanson, K. Y. Foo, E. R. Brown, and R. Denson, "Evaluation and characterization of a rubber-modified hot mix asphalt pavement," Transportation Research Record, no. 1436, pp. 98107, 1994.

[7] J. E. Huffman, "Sahuaro concept of asphalt-rubber binders," in Proceedings of the 1st Asphalt Rubber User Producer Workshop, Scottsdale, Ariz, USA, 1980.

[8] D. R. Brown, D. Jared, C. Jones, and D. Watson, "Georgia's experience with crumb rubber in hot-mix asphalt," Transportation Research Record, no. 1583, pp. 45-51, 1997.

[9] G. W. Maupin Jr., "Hot mix asphalt rubber applications in Virginia," Transportation Research Record, no. 1530, pp. 18-24, 1996.

[10] E. Charania, J. O. Cano, and R. H. Schnormeier, "Twentyyear study of asphalt rubber pavement in Phoenix, Arizona," Transportation Research Record, vol. 1307, pp. 29-38, 1991.

[11] M. Stroup-Gardiner, B. Chadbourn, and D. E. Newcomb, "Babbitt, Minnesota: case study of pretreated crumb rubber modified asphalt concrete," Transportation Research Record, no. 1530, pp. 34-42, 1996.

[12] E. R. Brown and M. Hemant, "Evaluation of Labrotary properties of SMA mixture," Tech. Rep. 93-5, National Center for Asphalt Technology, Auburn University, 1993.

[13] M. Ratnasamy and B. K. Bujang, "Laboratory diameteral fatigue performance of SMA with cellulose oil palm fiber," American Journal of Applied Sciences, vol. 3, no. 9, pp. 2005-2010, 2006.

[14] A. Mahrez, Properties and performance of stone mastic asphalt reinforced with glass fibre [Ph.D. thesis], Faculty of Engineering, University of Malaya, Kuala Lumpur, Malaysia, 2008.

[15] C. A. O'Flaherty, Highway Engineering Textbook, Edward Arnold, London, UK, 3rd edition, 1988.

[16] P. S. Shaw, Stress-strain relationships for granular materials under repeated loading [Ph.D. thesis], Department of Civil Engineering, University of Nottingham, Nottingham, UK, 1980.

[17] W. Hadley, W. Hudson, and T. W. Kennedy, "A method of estimating tensile properties of materials tested in indirect tension,” Tech. Rep. 41, Center for Highway Research, Austin, Tex, USA, 1970. 
[18] S. Aflaki and M. Memarzadeh, "Using two-way ANOVA and hypothesis test in evaluating crumb rubber modification (CRM) agitation effects on rheological properties of bitumen," Construction and Building Materials, vol. 25, no. 4, pp. 20942106, 2011.

[19] L. Raad and S. Saboundjian, "Fatigue behavior of rubbermodified pavements," Transportation Research Record, no. 1639, pp. 73-82, 1998.

[20] N. S. Mashaan and M. R. Karim, "Investigating the rheological properties of crumb rubber modified bitumen and its correlation with temperature susceptibility," Materials Research, vol. 16, no. 1, pp. 116-127, 2013.

[21] M. Castro and J. A. Sánchez, "Estimation of asphalt concrete fatigue curves-a damage theory approach," Construction and Building Materials, vol. 22, no. 6, pp. 1232-1238, 2008.

[22] M. Arabani, S. M. Mirabdolazimi, and A. R. Sasani, "The effect of waste tire thread mesh on the dynamic behaviour of asphalt mixtures," Construction and Building Materials, vol. 24, no. 6, pp. 1060-1068, 2010.

[23] N. S. Mashaan, A. H. Ali, M. R. Karim, and M. Abdelaziz, "Effect of crumb rubber concentration on the physical and rheological properties of rubberised bitumen binders," International Journal of Physical Sciences, vol. 6, no. 4, pp. 684-690, 2011.

[24] N. S. Mashaan, A. H. Ali, M. R. Karim, and M. Abdelaziz, "Effect of blending time and crumb rubber content on properties of crumb rubber modified asphalt binder," International Journal of Physical Sciences, vol. 6, no. 9, pp. 2189-2193, 2011.

[25] N. S. Mashaan, A. H. Ali, M. R. Karim, and M. Abdelaziz, "An overview of crumb rubber modified asphalt," International Journal of Physical Sciences, vol. 7, no. 2, pp. 166-170, 2012.

[26] A. H. Ali, N. S. Mashaan, and M. R. Karim, "Investigations of physical and rheological properties of aged rubberised bitumen," Advances in Materials Science and Engineering, vol. 2013, Article ID 239036, 7 pages, 2013. 

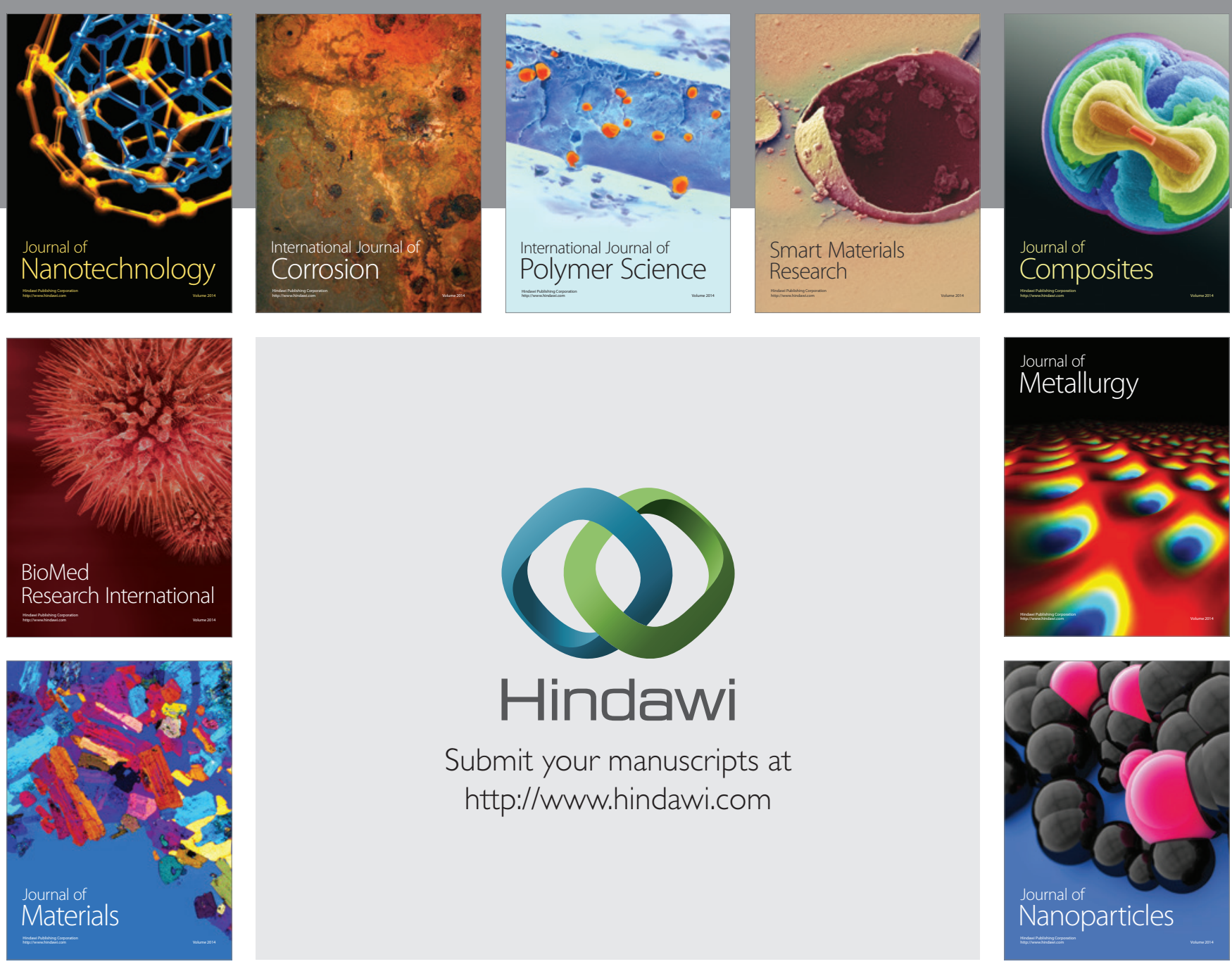

Submit your manuscripts at http://www.hindawi.com
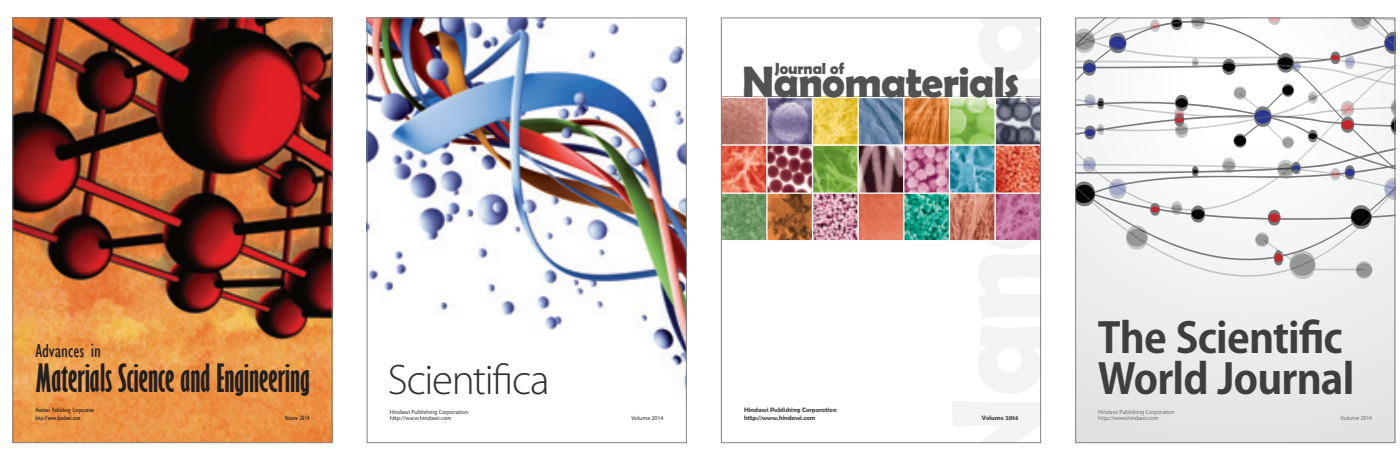

\section{The Scientific World Journal}
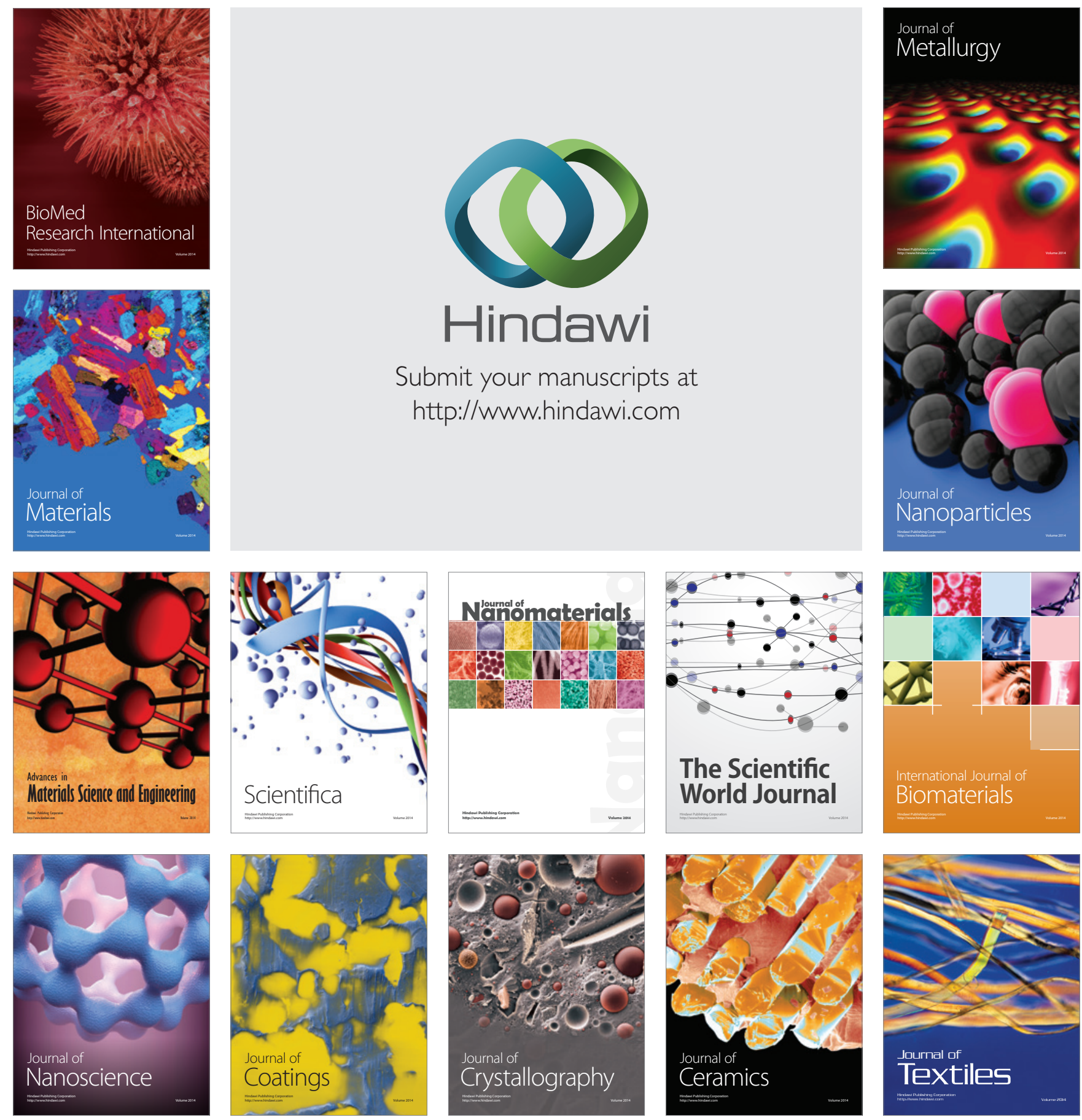